\title{
Helping survivors of human trafficking
}

Lujain Alhajji, MD, Vanessa Padilla, MD, Nicole Mavrides, MD, and JoNell Potter, PhD

$\mathrm{H}$ uman trafficking (HT) is a secretive, multibillion dollar criminal industry involving the use of coercion, threats, and fraud to force individuals to engage in labor or commercial sex acts. In 2017, the International Labour Organization estimated that 24.9 million people worldwide were victims of forced labor (ie, working under threat or coercion). ${ }^{1}$ Risk factors for individuals who are vulnerable to HT include recent migration, substance use, housing insecurity, runaway youth, and mental illness. Traffickers continue the cycle of HT through isolation and emotional, physical, financial, and verbal abuse.

Survivors of HT may avoid seeking health care due to cultural reasons or feelings of guilt, isolation, distrust, or fear of criminal sanctions. There can be missed opportunities for victims to obtain help through health care services, law enforcement, child welfare services, or even family or friends. In a study of 173 survivors of HT in the United States, $68 \%$ of those who were currently trafficked visited with a health care professional at least once and were not identified as being trafficked. ${ }^{2}$ Psychiatrists rarely receive education on HT, which can lead to missed opportunities for identifying victims. Table 1 lists screening questions psychiatrists can ask patients they suspect may be trafficked.

\section{The psychiatric sequelae of trafficking} Survivors of HT commonly experience psychiatric illness, substance use, pain, sexually transmitted diseases, and unplanned pregnancies. ${ }^{3}$ Here we discuss some of the psychiatric conditions that are common among HT survivors, and outline a multidisciplinary approach to their care.

\section{Table 1}

\section{What to ask a patient you suspect may be a victim of human trafficking}

Are you able to come and go as you please?

Where do you sleep and eat?

Does someone hold your identification documents?

What type of work do you do?

Have you ever been forced to exchange sex for food or shelter?

Have you been asked to have sex with multiple partners?

Do you have to meet a quota of money before you are able to leave work and go home?

Have threats from your employer made you fearful about leaving your job?

PTSD, mood disorders, and anxiety disorders. Studies suggest survivors of HT who seek care have a high prevalence of depression, anxiety, and posttraumatic stress disorder (PTSD). ${ }^{3}$ Survivors may have experienced multiple repetitive trauma, such as physical and sexual abuse. ${ }^{3}$ Compared with survivors of forced labor trafficking, survivors of sex trafficking have higher rates of childhood abuse, violence during trafficking, severe symptoms of PTSD, and comorbid depression and PTSD. ${ }^{4}$ For survivors with PTSD, consider psychosocial interventions that address social support, coping strategies, and community reintegration. ${ }^{5}$ Survivors can also benefit from trauma-informed care that focuses on the cognitive aspect of the trauma, such as cognitive processing therapy, which involves cognitive restructuring without a written account of the trauma. ${ }^{6}$

Substance use disorders. Some individuals who are trafficked may be forced to use
Dr. Alhajji is Assistant Professor, Department of Psychiatry and Behavioral Sciences, University of Miami Miller School of Medicine, Miami, Florida. Dr. Padilla is Assistant Professor and Director, ConsultationLiaison Psychiatry Fellowship Program, University of Miami Miller School of Medicine, Miami, Florida. Dr. Mavrides is Assistant Professor, Director, Child and Adolescent Psychiatry Fellowship Program, and Medical Director, Child and Adolescent Psychiatry Consultation-Liaison Program, University of Miami Miller School of Medicine, Miami, Florida. Dr. Potter is Professor of Clinical Obstetrics, Gynecology and Reproductive Sciences, Vice Chair, Reproductive Sciences, and Chief, Women's HIV Service, Director, THRIVE Clinic, University of Miami Miller School of Medicine, Miami, Florida.

Disclosures

Dr. Alhajji receives federal funding from the Department of Justice Office for Victims of Crime. The other authors report no financial relationships with any companies whose products are mentioned in this article, or with manufacturers of competing products.

doi: $10.12788 /$ cp.0093 
Survivors of

human trafficking

have a high

prevalence of

depression, anxiety, and PTSD

\section{$f$}

Discuss this article at www.facebook.com/ MDedgePsychiatry $\mathbf{0}$

\section{Table 2}

\section{The PEARR Tool: A trauma-informed approach to victim assistance}

\begin{tabular}{l|l} 
Step 1: Provide & - Provide the patient with a safe and private setting \\
privacy & $\begin{array}{c}\text { Consider strategies to separate the patient from their companion } \\
\text { in a non-threatening manner } \\
\text { - Explain any limits to confidentiality (eg, mandatory reporting for minors) }\end{array}$ \\
\hline Step 2: Educate & $\begin{array}{l}\text { Educate the patient about abuse, neglect, and violence in a nonjudgmental } \\
\text { manner that normalizes sharing information } \\
\text { - Provide the patient with educational brochures/contact information } \\
\text { (eg, local service providers, national hotlines) } \\
\text { - Screen the patient for abuse, neglect, or violence } \\
\text { - If there are risk factors/indicators of victimization, ask about these concerns } \\
\text { - If the patient denies victimization or declines assistance, then respect }\end{array}$ \\
\hline $\begin{array}{l}\text { Step 4: Respect } \\
\text { and Respond }\end{array}$ & $\begin{array}{c}\text { Offer the information about resources that can assist the patient in the event } \\
\text { of an emergency (eg, local service providers, crisis hotlines) } \\
\text { - If the patient accepts help, consider referral to local resources, and provide } \\
\text { information for local/national resources as appropriate }\end{array}$ \\
\hline Source: Adapted from reference 8
\end{tabular}

drugs of abuse or alcohol, while others may use substances to help cope while they are being trafficked or afterwards. ${ }^{3}$ For these patients, motivational interviewing may be beneficial. Also, consider referring them to detoxification or rehabilitation programs.

Suicide and self-harm. In a study of $98 \mathrm{HT}$ survivors in England, 33\% reported a history of self-harm before receiving care and $25 \%$ engaged in self-harm during care. ${ }^{7}$ After engaging in self-harm, survivors of HT were more likely to be admitted to psychiatric inpatient units than were patients who had not been trafficked. ${ }^{7}$ It is crucial to conduct a suicide risk assessment as part of the traumainformed care of these patients.

Other conditions. In addition to psychiatric illness, survivors of HT may experience physical symptoms such as headache, back pain, stomach pain, fatigue, dizziness, memory problems, and weight loss. ${ }^{3}$ Referral to other specialties may be necessary for addressing any of the patient's other conditions.

\section{Use a multidisciplinary approach}

Treatment for survivors of HT should be tailored to their specific mental health needs by including psychopharmacology; individual, group, or family psychotherapy; and peer advocate support. Rehabilitation, social services, and case management should also be considered. The care of survivors of HT benefits from a multidisciplinary, culturallysensitive, and trauma-informed approach. Table $2^{8}$ describes the PEARR Tool (Provide privacy, Educate, Ask, Respect, and Respond), which offers physicians 4 steps for addressing abuse, neglect, or violence with their patients. Also, the National Human Trafficking Hotline (1-888-373-7888) is available 24/7 for trafficked persons, survivors, and health care professionals to provide guidance on reporting laws and finding additional resources such as housing and legal services.

\section{References}

1. International Labour Organization, the Walk Free Foundation. Global Estimates of Modern Slavery: forced labour and forced marriage. Published 2017. Accessed January 14, 2021. www.ilo.org/global/publications/ books/WCMS_575479/lang--en/index.htm

2. Chisolm-Straker M, Baldwin S, Gaïgbé-Togbé B, et al. Health care and human trafficking: we are seeing the unseen. J Health Care Poor Underserved. 2016;27(3):1220-1233.

3. Ottisova L, Hemmings S, Howard LM, et al. Prevalence and risk of violence and the mental, physical and sexual health problems associated with human trafficking: an updated systematic review. Epidemiol Psychiatr Sci. 2016;25(4):317-341.

4. Hopper EK, Gonzalez LD. A comparison of psychological symptoms in survivors of sex and labor trafficking. Behav Med. 2018;44(3):177-188.

5. Okech D, Hanseen N, Howard W, et al. Social support, dysfunctional coping, and community reintegration as predictors of PTSD among human trafficking survivors. Behav Med. 2018;44(3):209-218.

6. Salami T, Gordon M, Coverdale J, et al. What therapies are favored in the treatment of the psychological sequelae of trauma in human trafficking victims? J Psychiatr Pract. 2018;24(2):87-96

7. Borschmann R, Oram S, Kinner SA, et al. Self-harm among adult victims of human trafficking who accessed secondary mental health services in England. Psychiatr Serv. 2017;68(2):207-210.

8. Using the PEARR Tool. Dignity Health. Published 2019. Accessed January 14, 2021. https://www.dignityhealth. org/hello-humankindness/human-trafficking/victimcentered-and-trauma-informed/using-the-pearr-tool 